\title{
A FOTOPOESIA E O LETRAMENTO LÍRICO
}

\author{
Christina Ramalho ${ }^{1}$
}

\begin{abstract}
Resumo: Reflexões teóricas e críticas sobre a Fotopoesia, ou a arte de criar fotopoemas, como instrumento didático que auxilia no letramento lírico, por fundir duas linguagens, a fotográfica e a lírica, e promover, ao mesmo tempo, uma experiência lúdica de criação e a reflexão sobre o estar no mundo. A partir do diálogo com Cosson (2006), Gens (2010) e Pinheiro (2007) e de algumas referências à arte da fotografia, tais como as de Felizardo e Samain (2007) e Mauad (1996), entre outros, elaboro aqui considerações teóricas destinadas àqueles e àquelas que desejem se aprofundar nas possibilidades didáticas que a presença do fotopoema nas salas de aula pode proporcionar em termos de incentivo ao gosto pela leitura de poemas e à busca por olhares mais sensíveis à realidade que nos cerca. A essas reflexões, acrescento a descrição de uma proposta metodológica de realização de Oficina de Criação de Fotopoemas.
\end{abstract}

Palavras-Chave: Ensino de Literatura. Fotopoesia. Fotografia. Gênero lírico. Letramento lírico.

\section{PHOTOPOETRY AND LYRICAL LITERACY}

\begin{abstract}
Theoretical and critical reflections on Photopoetry, or the art of creating photopoems, as a didactic instrument that helps in lyrical literacy, by merging two languages, the photography and the poem, and promoting, at the same time, a playful experience of creation and reflection on being in the world. From the dialogue with Cosson (2006), Gens (2010) and Pinheiro (2007) and some references to the art of photography, such as those of Felizardo and Samain (2007) and Mauad (1996), among others, I elaborate here theoretical reflections aimed at those who wish to delve into the didactic possibilities that the presence of the photopoem in the rooms of classes can provide in terms of encouraging the taste for reading poems and the search for looks more sensitive to the reality that surrounds us. To these reflections, I add the description of a methodological proposal to conduct a Photopoem Creation Workshop.
\end{abstract}

Keywords: Literature teaching. Photopoetry. Photography. Lyrical genre. Lyrical literacy.

A imagem não é um objeto, não é uma coisa, ela é um ato posto diante de nós, oferecido aos nossos destinos. (ETIENNE SAMAIN, 2012, p. 162)

\footnotetext{
${ }_{1}^{1}$ Professora-Adjunta 4 do Curso de Letras da Universidade Federal de Sergipe, campus Itabaiana. Doutora em Letras pela UFRJ (2004), com Pós-Doutoramento em Estudos Cabo-Verdianos (USP/FAPESP, 2012) e Estudos Épicos (Université Clermont-Auvergne, 2017). Atua no Programa de Pós-Graduação em Letras (Estudos Literários) e no Programa de Mestrado Profissional em Letras (PROFLETRAS/ITABAIANA), da Universidade Federal de Sergipe.
} 


\section{Introdução}

No artigo "A poesia é o mundo sendo: o poema na sala de aula" (2014), tive a oportunidade de apresentar algumas reflexões sobre a presença do poema nas salas de aula de instituições de Ensino Básico e Ensino Superior que foram fruto do projeto de pesquisa intitulado "No meio do caminho tinha um poema: repensando as teorias e as práticas em torno dessa presença", que, na verdade, se tratou do projeto que marcou meu ingresso como professoraadjunta de Literaturas de Língua Portuguesa e Estágio Supervisionado no Curso de Letras da Universidade Federal de Sergipe, campus Itabaiana, em 2012. Naquela ocasião, partindo de bases teóricas - com destaque para Cereja (2005), Cosson (2006) e Paz (1982) - que incluíam documentos oficiais como os PCNs, elaborei testes de sondagem por meio dos quais faria um reconhecimento da presença (ou ausência) do poema como texto trabalhado em salas de aula do Curso de Letras da Universidade Federal de Sergipe e de instituições de Ensino Básico da região.

Após a aplicação dos testes em todas as turmas do curso de Letras da UFS/Itabaiana (2012) e em escolas do Ensino Básico - neste caso em projeto de Iniciação Científica (2012-2013) - o que pude, de modo geral, observar foi a grande ausência do poema nas salas de aula, principalmente no que tange a abordagens estéticas e culturais ao texto lírico, visto que o "uso" do poema ou de letras poéticas de canções como pretexto para exercícios gramaticais esteve, ocasionalmente, presente. Pouco se sabia sobre autores, produções regionais, temáticas recorrentes. Por outro lado, e ainda mais relevante, percebi a pouquíssima intimidade com a fruição lírica, tanto por parte de docentes como de discentes. Docentes, inseguros/as de sua capacidade de, por si mesmos/as, realizarem leituras bem sustentadas e interessantes de poemas, e oprimidos/as por cargas horárias imensas, raramente ousavam, por conta própria, enveredar com seus/suas estudantes pela fruição de poemas. Unindo os resultados das sondagens com a observação de livros didáticos, percebi também que o trabalho com o poema, como corpus instigante, convidativo e revelador, existia apenas em raros momentos de iniciativa particular de um/a ou outro/a docente, cujo interesse pela poesia advinha muito mais de um gosto pessoal do que propriamente de sua formação como docente. 
No âmbito específico do espaço universitário das Letras, motivada pelas conclusões a que cheguei, expressei algumas propostas:

[...] propõe-se aqui que também sejam urgentes as mudanças de postura por parte de docentes de literatura brasileira, teoria literária e leitura nas universidades, de modo a evitar que o traço de individualidade natural e positivo que as características de cada docente imprimem a cada curso de licenciatura em Letras não se sobreponha às reais necessidades de formação dos futuros professores. Que os cursos de licenciatura em Letras, além dessas marcas individuais, que destacam a própria trajetória de cada docente e seu envolvimento com temáticas específicas no campo da literatura e da língua, também tenham como princípio norteador o diálogo com a sociedade, com as questões específicas de cada contexto sociocultural e, também, com as expectativas dos discentes (2014, p. 367-368).

Essa colocação teve origem em outro aspecto observado: a pouca prática de se buscar, entre os/as estudantes, o conhecimento de seu gosto pela poesia, incluindo aí o gosto musical. Não recebi relatos de sondagens com os/as discentes para verificar seus conhecimentos sobre poesia e MPB, por exemplo. De certo modo, reconheci uma “cerimônia” ou um "protocolo de erudição", que criava um abismo entre o texto lírico e os/as estudantes. Era necessário, pois, fazer dos resultados obtidos uma base para a reflexão sobre a possibilidade de se promover maior aproximação entre textos líricos, docentes e discentes.

De lá para cá, ano a ano, meu envolvimento com estudos sobre a presença do poema nas salas de aula e o desenvolvimento de propostas e de ações voltadas para o incremento dessa presença ampliaram-se bastante. Foram fundamentais, nesse sentido, os projetos de extensão "Poetas modernos na escola I" (2013) e "Poetas modernos na escola II" (2014), que permitiram a interação entre graduandos/as do Curso de Letras de Itabaiana e estudantes do Ensino Fundamental e do Ensino Médio do Colégio Estadual 28 de Janeiro (hoje Centro de Excelência 28 de Janeiro), localizado na cidade de Monte Alegre de Sergipe, no sertão sergipano. Cada uma das duas ações envolveu um público de cerca de 500 pessoas em apresentações criativas sobre poetas modernos brasileiros, que aconteceram em dois turnos na escola, que liberou todas as 
turmas para participarem. A parceria, nesses projetos, com o professor e mestre Carlos Alexandre Nascimento Aragão, que atua como docente na escola, gerou, por sua vez, o projeto assinado por ele "A poesia indo à escola" (PIBIC Jr. da FAPITEC, 2015), que multiplicou, com modificações, as apresentações realizadas nos dois projetos acima citados, levando um grupo de 20 estudantes do Ensino Médio para diversas escolas do sertão sergipano com o objetivo de incentivar a presença do poema nas salas de aula e promover encontros com a poesia por meio de apresentações criativas. Esse projeto continua em vigor e é, sem dúvida, uma prova concreta de que o envolvimento de adolescentes e jovens com a linguagem lírica pode ser bem mais intenso do que se imagina.

Além desses projetos, muitos outros - entre ações de extensão internas, locais, regionais, nacionais e internacionais - foram acontecendo, ora de forma individual ora por meio do estabelecimento de parcerias, principalmente com o professor Aragão. Minha intenção foi dar materialidade ao objetivo de impulsionar novas visões e práticas envolvendo a presença do poema nas salas de aula brasileiras (e mesmo cabo-verdianas, como se verá na descrição a seguir). Assim, foram realizadas as ações: Nossas canções: poesia e MPB (curso de extensão em Itabaiana), em 2012; Oficina de Criação Literária I (curso de extensão em Itabaiana), em 2013; Oficina de criação: crônica e poema (curso de extensão em Itabaiana), em 2014; Poesia Ilustrada (PRODOCÊNCIA/CAPES, versões I a IV, em 17 escolas sergipanas e uma baiana), em 2014; organização do livro Olha o poema na escola (com o Prof. Dr. Beto Vianna, 2014, PRODOCÊNCIA/CAPES); I Noite de Gala da Poesia Contemporânea (PRODOCÊNCIA/CAPES, evento sobre poesia contemporânea envolvendo 70 graduandos/as do Curso de Letras Itabaiana, poetas e um público de 500 pessoas), em 2014; História da arte em diálogo com a poesia (curso de extensão em Itabaiana), em 2015; Noite de poesia no Murilo Braga (evento no Colégio Estadual Murilo Braga, em Itabaiana, envolvendo 67 graduandos/as do Curso de Letras Itabaiana e público de 400 estudantes da escola), em 2016; Em cena: Aglacy Mary (evento em homenagem à poesia da sergipana Aglacy Mary, em Itabaiana, envolvendo 17 graduandos/as do Curso de Letras Itabaiana e público de 500 pessoas), em 2017; Poesia Nordestina Brasileira na Escola Secundária de Chão Bom (evento realizado no Tarrafal, ilha 
de Santiago em Cabo Verde, com a participação presencial de 6 graduandas do Curso de Letras Itabaiana, de 2 doutorandos e de 1 mestrando do Programa de Pós-Graduação em Letras da UFS, 3 docentes da UFS e membros da Academia Gloriense de Letras e público estimado em 250 pessoas), em 2018; Seramagipepá: um amoroso neologismo da união (projeto de extensão que reuniu a Universidade Federal do Amapá e a Universidade Federal de Sergipe em ações voltadas para a divulgação virtual mútua de produções culturais locais, entre elas, a poesia ${ }^{2}$ ), em 2019; Oficina de Criação de Fotopoemas em assentamento do MST no sertão sergipano, em 2019; Oficina de Criação de Fotopoemas na Biblioteca Epifâneo Dória, em Aracaju, em 2019; e, finalmente, o Projeto Sergipe é Poesia! ${ }^{3}$ (2019, em andamento, em parceria com o professor Aragão), subdividido em ações iniciais de atualização/capacitação docente realizadas, individualmente, em municípios sergipanos (já concluídos: Curso de atualização Monte Alegre é Poesia!, Curso de Atualização Poço Redondo é Poesia!; Curso de Atualização Carira é Poesia!; Curso de Atualização Nossa Senhora da Glória é Poesia!), e cuja continuidade, de um lado, estenderá o projeto a estudantes dos municípios envolvidos e, de outro, levará a primeira etapa a outros municípios.

O Projeto Sergipe é Poesia!, de dimensões bastante ambiciosas, possibilitou que fosse criada a necessária ponte entre a universidade e as escolas, por meio do estabelecimento do diálogo com docentes de diferentes níveis do Ensino Básico das quatro primeiras cidades a que o projeto chegou. Uma formação, com dupla caráter de atualização/capacitação, com 60 horas de duração - na modalidade semipresencial - foi organizada, tendo como parâmetros diferentes formas de se abordar um poema. E a primeira oficina que integra o projeto trata-se da "Oficina de Fotopoesia".

Toda essa memória recuperada teve por finalidade explicar os antecedentes que levaram à ideia de se aproveitarem duas linguagens bastante ricas e instigantes, a fotografia e a poesia, para criar um método que pudesse acelerar, de um lado, a formação do gosto pela leitura de poemas e, consequentemente, a habilidade para chegar à fruição do texto lírico; e, de

\footnotetext{
${ }^{2}$ A página https://www.ramalhochris.com/seramagipepa disponibiliza o acesso às ações realizadas.

${ }^{3}$ A página https://www.ramalhochris.com/sergipe-e-poesia disponibiliza diversos materiais didáticos, descrição de ações, imagens, vídeos, oficinas etc.
} 
outro, incentivar a criação de poemas, aliando essa criação ao ato de fotografar. Tomando como ponto de partida o conceito de "letramento literário", de Rildo Cosson, definido como "processo de apropriação da literatura enquanto construção literária de sentidos" (PAULINO; COSSON, 2009, p. 67), cheguei ao que chamei de "letramento lírico" (2014), defendendo a ideia de que as especificidades do texto lírico exigiriam estratégias particulares para se chegar a esse letramento. Entre essas estratégias, esta tem sido, além de eficaz, bastante simples e prazerosa: fazer do trabalho de criação e fruição de fotopoemas um modo de aproximar docentes e discentes do gênero lírico. Afinal, se "O sucesso inicial do encontro do leitor com a obra depende da motivação" (COSSON, 2006. p. 54), não se pode negar, em tempos de realidade virtual e de grande valorização da imagem, que a fotografia se faz um elemento muito atraente para dar início ao investimento no letramento lírico.

Neste artigo, buscando criar um texto de consulta teórica sobre a fotopoesia e, ao mesmo tempo, objetivando apresentar as linhas gerais do desenvolvimento de oficinas de criação de fotopoemas, trago considerações sobre a linguagem fotográfica e o fotopoema como gênero textual híbrido. Primeiramente, abordarei de forma sucinta a presença do poema na sala de aula, relembrando colocações de Hélder Pinheiro no já clássico Poesia na sala de aula (2007) e de Armando Gens, outro pesquisador dedicado ao tema. Em seguida, apontarei alguns aspectos relacionados à fotografia como linguagem artística, para, então, chegar à fotopoesia como recurso didático, incluindo o detalhamento da oficina dedicada a essa prática.

Espero, com as reflexões aqui propostas, contribuir para a formação de uma base conceitual, crítica e metodológica sobre o fotopoema, manifestação híbrida, rica e instigante sobre a qual pouco se tem em termos de referências, mas que já se revelou recurso interessante para o letramento lírico.

\section{O poema na sala de aula}

É curioso, e mesmo triste, constatar que, muitas vezes, é preciso defender e justificar a importância de se lerem poemas. A aceleração do tempo, a pouca capacidade de concentração das pessoas, o imediatismo como traço 
comportamental, a supervalorização da matéria e do dinheiro, a pouca compreensão sobre o sentido de "estética" e de "arte", todos esses aspectos, entre muitos outros, parecem explicar a resistência ao texto lírico como fonte de conhecimento de mundo. Por mais que grandes escritores e pensadores, como Otacvio Paz, afirmem coisas como:

A poesia é conhecimento, salvação, poder, abandono. Operação capaz de transformar o mundo, a atividade poética é revolucionária por natureza; exercício espiritual, é um método de libertação interior. A poesia revela este mundo; cria outro. Pão dos eleitos; alimento maldito. Isola; une. Convite à viagem; regresso à terra natal (PAZ, 1982, p. 15).

Parece haver, entre as pessoas e o texto lírico, principalmente quando se exige dessas pessoas que interajam com um poema explicitando os sentidos que nele encontram, um caminho em cujo chão se atravessam um ou mais obstáculos. A presença mais aguda de recursos figurativos de linguagem, a constante intertextualidade literária e o convite implícito para se promoverem diálogos entre o poema e os diferentes contextos (filosóficos, históricos, geográficos, sociológicos, psicológicos, míticos etc.) a que ele remete são elementos que sugerem a necessidade de leitores/as maduros/as para que a fruição aconteça de forma mais plena e rica. Ao não se sentir maduro/a, um/a leitor/a pode, facilmente, esquivar-se do encontro com a poesia ou, tal como descreveu Paz, optar por não comer o "alimento maldito". E, para agravar a situação, pode-se facilmente ver no poema uma linguagem cuja sofisticação impede a eficácia comunicativa e faz dele um texto "sem grandes utilidades". Surge, mesmo que nem sempre de forma manifesta, a pergunta: "Para quê serve um poema?". E isso não é de se estranhar em tempos de utilitarismo como parâmetro regulador de práticas sociais.

Se essa questão é projetada no âmbito da escola ou mesmo da universidade, chega-se a uma complexidade ainda maior, pois, quando um/a docente traz o texto lírico como "conteúdo" de aula, ler ou não um poema deixa de ser uma decisão individual sobre um possível ato de lazer e passa a ser uma obrigação a ser cumprida. Não houve escolha, mas, em certo termo, imposição. Entretanto, antes de pensar nessa condição obrigatória de recepção, lembro do 
que afirmou Marisa Lajolo em Do mundo da leitura para a leitura do mundo (2006):

A discussão sobre a leitura, principalmente sobre a leitura numa sociedade que pretende democratizar-se, começa dizendo que os profissionais mais diretamente responsáveis pela iniciação na leitura devem ser bons leitores. Um professor precisa gostar de ler, precisa ler muito, precisa envolver-se com que lê (LAJOLO, 2006, p. 108).

Sem jamais querer esbarrar no vício de sempre se buscarem culpas nos/as docentes para os problemas relacionados à leitura e à interpretação de textos, quero, com a alusão a Lajolo, ressaltar um aspecto fundamental relacionado à presença do poema nas salas de aula: quando um/a docente leva para a aula um poema de que gosta e com o qual estabeleceu uma fruição prazerosa, ampliam-se imensamente as possibilidades de uma recepção mais simpática ao texto.

Partindo dessa constatação, lembro que Hélder Pinheiro (2007), sobre o trabalho com a poesia na escola, discrimina algumas condições que ele caracteriza como "indispensáveis" para que a presença do poema na sala de aula seja, de fato, uma experiência eficiente de investimento em leitura. A primeira delas é justamente uma experiência leitora docente significativa. Sendo assim, para trabalhar eficazmente com poemas em sua sala de aula, um/a docente precisa ser leitor/a de poesia. Por isso, em qualquer curso ou palestra que eu ministre para docentes, sempre destaco quão fundamental é que eles/as busquem, quando isso já não aconteça, se tornarem, de fato, leitores/as de poemas. Ao fazerem isso, certamente começarão a compor um repertório de leituras que lhes foram especialmente instigantes e que poderão, eventualmente, compartilhar - de forma entusiasmada e contagiante - com seus/as alunos/as.

A segunda condição apontada por Pinheiro refere-se ao interesse constante pelo repertório discente de leituras, de modo a ter um perfil mais real do "gosto" dos/as estudantes. Conhecer esse gosto, entretanto, não significa manter uma dependência com ele, mas aproveitar, por exemplo, temas que interessam a determinada turma, para, a partir de poemas selecionados, 
aproximar os/as estudantes dessa turma da poesia. Ao mesmo tempo, o/a docente pode, a partir de poemas selecionados, incrementar a sensibilização desse gosto sem que isso signifique atacar as afinidades dos/as estudantes com determinadas formas líricas, principalmente as que estão presentes (ou ausentes!) em letras de canções que lhes são caras.

A terceira condição se relaciona à preparação do ambiente no qual a experiência com o poema se dá. Pinheiro sugere recursos como leitura de poemas no pátio, uso de música, montagem de murais, incentivo à criação lírica. Entretanto, o aspecto mais relevante apontado pelo autor é que essa ambientação não seja algo extraordinário, mas uma constância no espaço da sala de aula e da escola. O poema precisa estar na vida, diariamente, como um alimento para a sensibilidade. E será um "alimento maldito" não porque possa envenenar, mas por levar a uma visão mais sensível e crítica do mundo.

A quarta condição se relaciona ao papel da instituição de ensino, que deve oferecer, em sua biblioteca, não só um acervo variado, que inclua livros de poemas de diferentes autores/as e épocas, mas também um espaço convidativo de interação com esses livros. Nesse sentido, Pinheiro faz referência às salas de leitura como espaços que podem contribuir para a qualidade do encontro dos/as estudantes com os textos líricos.

Outra contribuição importante de Pinheiro se relaciona à dimensão oral do encontro com o poema. Saber ler oralmente um poema é requisito fundamental para fazer o texto despertar interesse e sensibilidade. Ele aponta que:

As maiores dificuldades ocorrem com os poemas modernos. A falta de pontuação, as elipses, a ausência de uma direção de leitura, deixam-nos muitas vezes perplexos no contato inicial com a poesia moderna. Essas dificuldades, sem dúvida, algumas vezes podem afastar as pessoas da poesia. Muitos professores se confessam inseguros para ler um poema em voz alta para seus alunos (PINHEIRO, 2007, p. 33).

Ainda que esse fato - a dificuldade para ler oralmente um poema seja inegável e envolva tanto docentes como discentes, há soluções, e todas, certamente, passam pela leitura e releitura silenciosa do poema a ser lido 
oralmente até que se chegue à compreensão das demandas de trabalho com a voz que os sentidos do poema constroem.

Destaco, ainda, nesta abordagem sucinta sobre a presença do poema na sala de aula, algumas considerações de Armando Gens, em "Sobre o poema, o poeta, o livro" (2010). Uma de suas afirmações mais contundentes é a seguinte:

Professores atentos aos diferentes contextos das escolas brasileiras observam que o poema não se harmoniza com os propósitos mais diretas da tradição escolar do ensino de leitura e escrita. De modo geral, esta tradição se centra na fixação de padrões, normas e tipologias. A consequência de tal concentração é que se dá ao desvio muito tento: o texto literário só tem significativo rendimento quando permite o exercício de descrições gramaticais legitimadas e ser como mostruário de escrita modelar (GENS, 2010, p. $4-5)$.

Essa colocação de Gens se alinha com o que há pouco afirmei sobre o utilitarismo como prática para definir o que é e o que não é interessante para a formação de um/a estudante. Além disso, Gens também assinala certas questões de gênero relacionadas ao gênero lírico tradicionalmente visto como uma manifestação mais afeita ao universo feminino. Nesse âmbito, salienta o autor: "Aqui, a interferência do professor torna-se fundamental para que tais construções culturais sejam desnaturalizadas" (2010, p. 5). Ou seja, o/a docente contribuirá para se descontruir a ideia de que poemas são "coisas de menina", para valorizá-los como formas de expressão acessíveis a quem se interesse por esse tipo de arte. Formas de expressão que podem levar a um encontro profundo com a própria língua.

Sobre a capa de hermetismo com que se vestem os poemas, Gens destaca que uma das razões está “na ausência de protocolos de leitura que possam franquear a efetivação de pactos entre a comunidade leitora e o poema, de modo que a referida comunidade possa manter com o poema um jogo de infinitas possibilidades" (GENS, 2010, p. 6). No caso específico deste artigo, considero o trabalho com o fotopoema uma forma de pacto, no sentido apontado por Gens. E sobre esse pacto discorrerei mais adiante. 
Uma última referência se relaciona aos termos "poesia" e "poema", em geral tratados como sinônimos. Esse tratamento equivocado se explica sem dificuldade se caminharmos por trilhas metonímicas, afinal, entre "poesia" e "poema", há um campo semântico com traços comuns relevantes. No entanto, ao não se fazer a distinção, não se percebe que a palavra poesia, por nos remeter à abstração do belo e à sua criação, extrapola o texto material que é o poema, como gênero textual literário que possui características bem peculiares, como uso padronizado ou inventivo de versos, estrofes, rimas, métrica, ritmos, recurso gráficos etc. Conforme salienta Gens: “o sentido do termo 'poesia' tem longo alcance e se reveste de ambiguidades se exposto à investigação semântica" (GENS, 2010, p. 7). A poesia está nas artes, na natureza, no ser humano, nos acontecimentos. Está em tudo aquilo que, por conter elementos que tocam diretamente a emoção e a razão humanas, promove a experiência estética de "viver o mundo" através de palavras que levam a imagens, sons, texturas, aromas e sabores. Conhecer o sentido profundo de poesia nos leva, inclusive, a entender que a forma "poema", reconhecida pela presença de versos, estrofes, rimas etc., não garante que o texto contenha "poesia". Dito isso, concluirei esta parte com uma última reflexão diretamente relacionada ao trabalho com fotopoemas. Vou a ela.

Em minha concepção, só consegue, realmente, vivenciar toda a capacidade de emocionar e provocar reflexões que um poema possui quem alcança ver a poesia do e no mundo. Logo, como investir no letramento lírico sem passar pela experiência de se buscar a poesia que está contida na vida? Por outro lado, se voltarmos à ideia de que um poema - quando contém poesia pode provocar, a partir das palavras, relações e experiências imagens, sons, texturas, aromas e sabores, facilmente perceberemos que, entre os sentidos ligados a cada uma dessas experiências, destaca-se a maior intimidade do ser humano, mais ainda em nossos dias, com as imagens, visto que quem conduz esse encontro é a visão, sentido sobre o qual temos uma percepção muito mais concreta. Com exceção, por razões óbvias, de pessoas que apresentam condições de visão limitadas ou inexistentes, é a partir do que vemos que construímos nossa relação com o espaço e os outros seres. Não à toa surgiu a máxima "O que os olhos não veem o coração não sente". 
Essa intimidade com o "ver" - ainda que não discutamos aqui a qualidade que leva o "ver" a se tornar "olhar" - pode, sim, ser um excelente ponto de partida para se promover a busca pela poesia do mundo e, na sequência, gerar o encontro com a beleza de um poema. Por isso, defendo aqui o uso da fotografia como elemento de mediação inicial entre o ser, o mundo e a poesia e, depois, o fotopoema, como elemento de fusão entre o ver, o olhar e a palavra que traduz o olhar alcançado. Para melhor explicar a proposta, recorrerei, como primeiro passo, a algumas considerações sobre a fotografia.

\title{
A fotografia e sua arte de dizer o mundo
}

\author{
Pensar o objeto fotográfico, em sentido amplo, \\ refere-se à apropriação. A apropriação do real \\ e sua transformação em realidade captada e revelada, \\ capaz de reproduzir um espaço que foi visto \\ e capturado por uma lente e transferido na sua \\ imortalidade de objeto revelado para todo e qualquer \\ olhar que a ele se atenha (KOURY, 2004, p. 131).
}

Inicio esta parte do artigo sublinhando que, evidentemente, não há espaço aqui para uma retomada diacrônica - e interessante - do trajeto da fotografia como técnica e arte universal e, muito menos, de sua história no território brasileiro. Contudo, reproduzo colocações de Felizardo e Siaman que se prestam muito bem para descrever o papel da fotografia na sociedade:

A fotografia foi um fenômeno que revolucionou a memória, a sociedade da época e o pensamento moderno. A concepção e visão de mundo se alteraram a partir do seu advento. Ela, com sua chamada visão imparcial, precisa, metódica, inequívoca, muito contribuiu nos campos da evolução tecnológica, informativa, dedutiva, historiadora, do campo social e antropológico (FELIZARDO; SIAMAN, 2007, p. 215).

A fotografia logrou alcançar, com precisão, um sentido de "realidade transfigurada" que, em muitas épocas da história das Artes Plásticas, foi objetivo de pintores/as e escultores/as. Por meio de um objeto, de uma máquina, o ser humano desenvolveu a técnica de reproduzir no papel cenas da 
realidade, fazendo, respectivamente, dessa máquina, a câmera fotográfica, e da ação a ela relacionada, fotografar, instrumento e meio para se elaborar uma memória concreta da história. Uma história, entretanto, que se torna um produto cultural, visto que mediado pelo olhar do/a fotógrafo/a que elege as cenas capturadas a partir de uma sensibilidade própria, fazendo, também uso de recursos técnicos que, orientados por essa sensibilidade, podem imprimir valor estético - ou poesia - à fotografia realizada. Por essa razão, Mauad (1996) afirma que:

A fotografia deve ser considerada como produto cultural, fruto de trabalho social de produção sígnica. Neste sentido, toda a produção da mensagem fotográfica está associada aos meios técnicos de produção cultural. Dentro desta perspectiva, a fotografia pode, por um lado, contribuir para a veiculação de novos comportamentos e representações da classe que possui o controle de tais meios, e por outro, atuar como eficiente meio de controle social, através da educação do olhar (MAUAD, 1996, p. 83).

Mauad, no artigo acima referenciado, que se intitula "Através da imagem: fotografia e história interfaces" (1996), aborda a faceta da fotografia que a insere no âmbito das fontes históricas. No entanto, para mostrar a ambiguidade da fotografia, ela retoma a origem dessa técnica para sublinhar dois olhares distintos que, desde então, projetaram, simultaneamente, a fotografia no campo da realidade e no da arte, visto que a inventividade se fez presente na captura de imagens desde um de seus inventores, o pintor, fotógrafo e inventor francês Louis Jacques Mandé Daguerre (1787-1851). Vejamos:

A fotografia surgiu na década de 1830 como resultado da feliz conjugação do engenho, da técnica e da oportunidade. Niépce e Daguerre - dois nomes que se ligaram por interesses comuns, mas com objetivos diversos - são exemplos claros desta união. Enquanto o primeiro preocupava-se com os meios técnicos de fixar a imagem num suporte concreto, resultado das pesquisas ligadas à litogravura, o segundo almejava o controle que a ilusão da imagem poderia oferecer em termos de entretenimento (afinal de contas, ele era um homem do ramo das 
diversões). É bem verdade que no século XIX a distinção entre técnica e magia não era tão clara quanto hoje, como bem ilustra o nome de uma das primeiras lojas de venda de material para eletricidade no Rio de Janeiro: "Ao Grande Mágico".

Desde então e ao longo de sua história, a fotografia foi marcada por polêmicas ligadas aos seus usos e funções. Ainda no século XIX, sua difusão provocou uma grande comoção no meio artístico, marcadamente naturalista, que via o papel da arte eclipsado pela fotografia, cuja plena capacidade de reproduzir o real, através de uma qualidade técnica irrepreensível, deixava em segundo plano qualquer tipo de pintura (MAUAD, 1996, p. 74).

Assim, ainda que a técnica seja um componente fundamental da fotografia, há um segmento de produções fotográficas que extrapola o mero registro realista de uma cena - com intenções de compor fonte histórica ou memória do vivido - e penetra naquilo que, mais acima, apontei como a poesia do mundo. Em vista disso, há uma gama imensa de variações entre o que, em princípio, reconheceríamos apenas como "fotografias". E tudo isso se torna ainda mais complexo quando o mundo entra na era digital, levando imagens a circularem virtualmente pelo planeta, sem a necessidade da versão em papel da imagem capturada. Sobre esse e outros temas, Etienne Samain, no artigo “As peles da fotografia: fenômeno, memória/arquivo, desejo" (2012), dimensiona “a chamada 'civilização das imagens', isto é, essa chuva de imagens que, ao mesmo tempo, nos provoca, nos ensina, nos inunda e nos satura" (2012, p. 155), reconhecendo, entre outros atributos, seus vínculos com o que chama de "ordem das coisas vivas":

As imagens pertencem à ordem das coisas vivas, ao mesmo título que os problemas de beleza, os caranguejos do mar, as orquídeas e os seres humanos. Explico-me. Se admitirmos que a imagem (toda imagem) é um fenômeno, isto é, "algo que vem à luz [phanein]", “algo que advém”, um "acontecimento" (um "advento" como melhor se dizia, outrora), entender-se-ia que ela é, ainda, uma "epifania", uma "aparição" [epiphanein], uma "revelação", no sentido até fotográfico do termo (SAMAIN, 2012, p. 157). 
O que uma fotografia revela, portanto, pode extrapolar esse registro factual do vivido e penetrar no simbólico. Pode nos fazer pensar no sentido que se estabelece entre os signos que integram o todo da imagem, pode nos levar a um campo semântico vasto, que se multiplica cada vez que o "olhar" se aprofunda. Por isso, "É necessário, pois, abrir a imagem, desdobrar a imagem, 'inquietar-se diante de cada imagem' (Didi -Huberman, 2006b). Furar e romper a superfície" (SAMAIN, 2012, p. 159).

Por esse viés, podemos compreender que há fotografias que nos convidam a um profundo exercício de leitura visual, que, segundo o que aqui defendo, pode ser um primeiro passo importante rumo à busca pela poesia do mundo. Despertar, em nossos/as estudantes, essa capacidade de ir além do ver e alcançar o olhar, trabalhando com imagens fotográficas, nos aproxima desses/as estudantes, visto que estamos fazendo uso de um contexto que lhes é íntimo, pois são representantes autênticos dessa "civilização das imagens". Passo, então, a pensar, na relação entre fotografia, ensino e poesia.

\section{A fotografia e a fotopoesia como recursos didáticos}

Retomando um comentário feito na primeira seção deste artigo, destaco que os biólogos Marilia Dammski Borges, José Marcelo Aranha e José Sabino, em "Fotografia de natureza como instrumento para educação ambiental" (2010), trazem uma importante consideração inicial sobre um dos sentidos por meio do qual nos relacionamos com o mundo, a visão:

A visão é um dos sentidos mais importantes nos humanos. Para Berne e Levy, (1998) a visão evoluiu como sentido dominante nos primatas, o que levou a espécie humana a depender da visão para a comunicação. Douglas (2000) afirma que, dentro dos sistemas sensoriais da espécie humana, a visão é um dos sentidos mais evoluídos, permitindo conhecer o mundo externo, pela formação de imagens em um receptor específico localizado na retina. Então, o cérebro recebe impulsos elétricos gerados na retina e interpreta as imagens ópticas determinando a sensação visual propriamente dita (2010, p. 150). 
A partir do reconhecimento da importância da visão como forma de conexão sensível com o mundo, os autores desenvolvem pertinentes reflexões sobre o uso didático da fotografia na formação de uma consciência ecológica, tão necessária em tempos de grandes violações ao Meio Ambiente. Para defender seu ponto de vista sobre a fotografia como recursos didático eficaz, os autores analisam o impacto que algumas fotografias geram no público que entra em contato com elas. Além disso, reconhecem diferentes níveis de sensibilidade e percepção, que levam uma mesma fotografia a ser vista de formas diversas e em graus distintos de reconhecimento de signos. Daí também o ponto de vista de que a cada contemplação podem ser descobertas novas provocações semânticas em uma fotografia.

Outro aspecto levantando pelos autores se refere à circulação da fotografia pelos diferentes meios de comunicação e linguagens:

Os diversos meios de comunicação e informação jornalística, publicitária ou cultural que nos envolvem e fascinam, são essencialmente fotográficos, seja na forma de imagens estáticas ou dinâmicas. A fotografia, impressa, exposta ou projetada, sempre está presente. Sem dúvida, a fotografia integrou-se definitivamente em várias áreas das atividades humanas, proporcionando processos criativos na busca de novos patamares do conhecimento, em todas suas formas e níveis (BORGES; ARANHA; SABINO, 2010, p. 152).

As considerações dos autores, ao relacionarem fotografia, ensino de Biologia e investimento na consciência ecológica, servem para sustentar visão semelhante, aqui manifestada, que considera a fotografia como um recurso viável, instigante e útil para o contato com o sentido do poético. E isso se dá justamente pela ambiguidade que a linguagem fotográfica possui - e aqui sublinho que me refiro a fotografias que integram técnica e arte - e à decorrente necessidade de se transformar o ver uma fotografia em olhá-la, para se penetrar mais agudamente nos sentidos possíveis. Borges, Aranha e Sabino ainda destacam que:

Ao fornecer um sem número de possibilidades plásticas e/ou gráficas, a fotografia provoca dúvidas, gera questionamentos e sugere soluções na busca de 
resultados, tanto para artistas quanto para cientistas, e também ao homem comum, em sua contemplação desinteressada (ou não) do mundo que o cerca (BORGES; ARANHA; SABINO, 2010, p. 152).

São justamente essas dúvidas e questionamentos que nos colocam em contato com a experiência poética. Abandonamos a mera referencialidade das coisas retratadas para penetrarmos na simbologia dos elementos presentes na fotografia. E, para melhor compreender esse tipo de fotografia, precisamos, inclusive, abandonar conceitos culturalmente impostos a nós, como "beleza" e "feiúra", pois, somente assim, entenderemos que a poesia é uma forma de libertação de padrões impostos em nome da busca por sentidos mais sensíveis, problemáticos, políticos, afetivos etc. Quando um/a estudante analisa fotografias de elementos da natureza feitas com arte, será conduzido à problematização da relação do ser humano com esses elementos. Basta, claro, que a mediação docente parta de uma fruição prévia que o/a capacite como mediador/a para explorar didaticamente a fotografia ou fotografias em questão. O mesmo se dará quando um/a professor/a de língua e literatura buscar em imagens fotográficas possibilidades de despertar em seus/suas alunos/as a compreensão do sentido da beleza poética, como veremos, mais adiante, quando passarmos a dimensionar essa prática em forma de oficina.

Ainda para pensar no potencial da fotografia e, em seguida, do fotopoema, como recurso didático para incrementar a qualidade na leitura de poemas, a ponto de configurar um letramento lírico bem-sucedido, lembro a definição de fotografia proposta por Mauad:

A fotografia - para além da sua gênese automática, ultrapassando a ideia de analogon da realidade - é uma elaboração do vivido, o resultado de um ato de investimento de sentido, ou ainda uma leitura do real realizada mediante o recurso a uma série de regras que envolvem, inclusive, o controle de um determinado saber de ordem técnica (MAUAD, 1996, p. 75).

Se a fotografia revela uma "elaboração do vivido" podemos dizer que ela é plenamente compatível com o poema, pois, como arte literária, o poema faz uso da palavra para elaborar o sentido do vivido. Os meios de o poema fazer 
isso é que são distintos dos da fotografia, cuja dimensão técnica parece mais palpável por existir uma máquina mediando o olhar para o mundo.

Também por associação, podemos contrapor a figura do/a fotógrafo/a à do/a poeta. Fotografar algo não faz de quem fotografou um/a artista da fotografia assim como escrever um texto em versos não faz de ninguém um/a poeta. Há, além da competência técnica para o uso da câmera, no caso do/a fotógrafo/a, e para o uso da palavra, no caso do/a poeta, a necessidade de um investimento na poesia, ou seja, naquilo que, como já destacamos, extrapola a mera realidade e nos projeta, simultaneamente na emoção do sentir e no desafio do pensar. Cibele Abdo Rodella fala sobre o que chama de "fotografia poética":

A fotografia poética por sua vez nasce do interesse do artista em manifestar algo, em representar a natureza ou de intervir nesta natureza com elementos que despertem uma manifestação qualquer. A foto poética é livre enquanto depende da criatividade sem limites do artista. A intencionalidade do autor deste tipo de imagem é produzir sensações, leituras muito mais nos campos estéticos e sensíveis do que do informativo, e muitas vezes estas imagens são produzidas sem intencionalidade, já que o artista tem uma postura menos "racional" frente à sua obra - o que importa na maioria dos casos é a criatividade, a intuição a sensibilidade, menos que o raciocínio articulado do repórter fotográfico (RODELLA, 2009, p. 1048).

Como se vê, há, nesse tipo de fotografia, um trabalho conceitual, um investimento no simbólico. Por tudo isso, levar fotografias e fotopoemas para a sala de aula e, mais, incentivar a produção de fotopoemas não pode prescindir de alertar os/as estudantes envolvidos/as sobre a constante busca por aperfeiçoamento técnico (tanto do/a fotógrafo/a quanto do/a poeta) e ampliação da própria sensibilidade para perceber o mundo. Caso contrário, banalizaríamos as duas artes e acabaríamos contribuindo para o achatamento cultural que tem feito uma massa imensa de pessoas não serem mais capazes de discernir limites entre o que promove o aprofundamento do sentir e do pensar e o que, na contramão do humano, nos transforma em seres insensíveis, e às vezes até violentos e inumanos. 
Dito tudo isso, o que seria, de fato, um “fotopoema”? Visto que não há, propriamente, uma teoria definida sobre essa forma criativa, trato aqui, de forma bem simples, de conceituar fotopoemas como criações que mesclam duas artes: a fotografia e a poesia. Sobre o tipo de fotopoema de que trato, cabe dizer que essa mescla integra imagem e texto no mesmo espaço, ou seja, o texto lírico, feito a partir de uma imagem, integra-se a ela, o que requer cuidados técnicos e igual sensibilidade, para que uma arte não destrua a beleza da outra. Convém igualmente lembrar que há outras visões, como as de Teresa Vignoli, poeta, e Ronaldo Miranda Barbosa, fotógrafo, que, juntos, realizaram o projeto "Fotopoemas: uma questão de moldura"4. Em seu trabalho, poema e fotografia são colocados lado a lado, e o diálogo é feito com o olhar que vai e volta da fotografia ao poema e vice-versa. O fotopoema, no entendimento aqui exposto, não isola as duas produções. O texto é, harmonicamente, inserido na imagem, logo, há critérios técnicos próprios sobre os quais discorrerei mais adiante.

Já Dutra, Santos e Silva, no artigo “Uso das novas tecnologias para a produção textual do gênero fotopoema em inglês" (2014), discorrem sobre o fotopoema como recurso didático para o ensino de língua inglesa. Contudo, há na proposta um caráter mais prático, que valoriza o uso da língua inglesa em si, e não, propriamente, a dimensão poética que uma fotografia e um texto podem ter. Assim, o corpus em questão não é a fotografia artística, mas apenas o registro fotográfico em si e a técnica de fazer uso de canais como o Facebook (hoje falaríamos no Instagram), por exemplo, para envolver estudantes em práticas mais afeitas à sua realidade. Não é esse o foco do que aqui exponho, dado o objetivo de promover o trabalho com o poema em sala de aula, o que requer, de fato, o cuidado com todos os detalhes técnicos e criativos que envolvem tanto a fotografia a ser feita quanto o texto lírico que, a partir dela, nascerá.

Também é preciso salientar que a complexidade logo se instala, se nos damos conta de quão difícil é definir o que, no âmbito dessa fusão entre duas linguagens distintas em sua materialidade, pode ser considerado "artístico" ou "poético". E essa complexidade se aprofunda quando falamos do fotopoema como recurso didático, visto que, por exemplo, ao trabalhar, em sala de aula,

${ }^{4}$ Ver https://www.preface.com.br/projetos/39. 
com a criação de fotopoemas, um/a docente não estará lidando com profissionais da fotografia - nem ele/a mesmo/a será um/a profissional - nem com poetas experientes ou maduros/as. Logo, o nível de exigência em relação a ambas as linguagens deve ser compatível com o grupo com o qual se trabalha, levando em consideração, também, a faixa etária e o repertório de conhecimentos sobre fotografia e poesia dos/as discentes envolvidos/as. Finalizando esta seção, é válido retomar considerações de Mauad (1996) sobre as condições de recepção envolvidas na fruição da imagem fotográfica:

À competência do autor corresponde a do leitor, cuja exigência mínima é saber que uma fotografia é uma fotografia, ou seja, o suporte material de uma imagem. $\mathrm{Na}$ verdade é a competência de quem olha que fornece significados à imagem. Essa compreensão se dá a partir de regras culturais, que fornecem a garantia de que a leitura da imagem não se limite a um sujeito individual, mas que acima de tudo seja coletiva. A ideia de competência do leitor pressupõe que este mesmo leitor, na qualidade de destinatário da mensagem fotográfica, detenha uma série de saberes que envolvem outros textos sociais. A compreensão da imagem fotográfica, pelo leitor/destinatário, dá-se em dois níveis, a saber:

nível interno à superfície do texto visual, originado a partir das estruturas espaciais que constituem tal texto, de caráter não-verbal; e

nível externo à superfície do texto visual, originado a partir de aproximações e inferências com outros textos da mesma época, inclusive de natureza verbal. Neste nível, podem-se descobrir temas conhecidos e inferir informações implícitas. (MAUAD, 1996, p. 81)

Como se pode concluir, por meio de uma associação entre o que Mauad destaca e o que aqui se defende, o investimento no letramento lírico a partir da interpretação e mesmo da criação de fotopoemas não pode prescindir de uma mediação que considere as condições de recepção e invista na necessária contextualização sobre as duas linguagens envolvidas nesse processo: a fotográfica e a lírica. 
Ao descrever, a seguir, como se pode realizar uma "Oficina de interpretação e criação de fotopoemas", darei formas mais concreta a todas as reflexões até aqui desenvolvidas.

\section{Oficina de interpretação e criação de fotopoemas}

A realização de uma "Oficina de interpretação e criação de fotopoemas" não supõe públicos específicos. Essa afirmação nasce de experiências práticas por mim vividas, visto que tanto ofereci essa oficina a docentes que participaram dos cursos de atualização/capacitação do Projeto Sergipe é Poesia! já citados, como dentro da disciplina optativa "Experiências de Criação Literária" (2018/1, 2018/2 e 2019/1); na Biblioteca Estadual Epifâneo Dória (Aracaju, 2019), para público variado; e mesmo em um contexto bastante especial, quando a ofereci a moradores/as de diferentes faixas etárias de um assentamento do MST no sertão sergipano (2019). Além disso, tive acesso aos resultados de realizações da mesma oficina que foram desenvolvidas por docentes que participaram do Sergipe é Poesia!.

Algumas das oficinas que realizei resultaram em produções que, reunidas na forma de "mostra de fotopoemas" - especificamente "Tempo de feira" e "Poética dos detalhes: campus Itabaiana" -, foram exibidas no campus Itabaiana, na Bienal do Livro de Itabaiana (2019), na Bilioteca Epifâneo Dória em Aracaju, na Biblioteca Municipal de Nossa Senhora da Glória e na Secretaria Municipal de Educação de Monte Alegre de Sergipe. A mostra "Poética dos detalhes: campus Itabaiana", reunindo fotopoemas criados por 14 graduandos/as da terceira turma da disciplina Experiências de Criação Literária, foi ainda mais longe: em março de 2020 foi exibida na Université de Poitiers, na França, após trabalho de tradução dos textos para o francês, em ação desenvolvida em parceria com a Professora-Doutora Karina Marques, que atua na universidade e desenvolveu o projeto de tradução com seus alunos e suas alunas. Essa mesma mostra será, ainda, exibida em breve na Universidade do Porto em Portugal.

Destacadas, portanto, as experiências, que comprovam a diversidade de público com o qual se pode desenvolver a oficina aqui proposta e os resultados possíveis, em termos de se estimular ainda mais o envolvimento 
dos/as participantes com esse gênero, descrevo, de forma sintética, como a oficina se estrutura, destacando ser essa uma oficina a ser realizada no espaço escolar (o que não impede de se aproveitarem suas etapas para realização em outros espaços). Descreverei, a seguir, cada uma das 6 etapas que a compõem.

\subsection{Etapa 1: Uma conversa sobre a arte da fotografia}

Essa etapa tem dois objetivos principais: realizar uma sondagem por meio de conversa oral - para conhecer as informações (ou a bagagem de conhecimentos) que o grupo envolvido na oficina tem sobre a arte da fotografia; e apresentar informações contextuais básicas que complementem esse conhecimento.

Como cada grupo, a depender do nível de ensino e da faixa etária, além de outras especificidades das turmas, exigirá grau diferente de aprofundamento nas informações contextuais, o/a docente deve produzir seu próprio material informativo, de modo que possa contar um pouco da história da fotografia.

Minha sugestão, também a partir das experiências que já realizei, é selecionar imagens de um grande nome da fotografia brasileira para mostrar ao grupo, de modo a explorar sua capacidade de "ver", "olhar" e "compreender" os sentidos possíveis das imagens trabalhadas. Nesse particular, indico fortemente o nome de Sebastião Salgado ${ }^{5}$, sem dúvida o maior expoente brasileiro na Fotografia universal, cujas imagens, disponibilizadas fartamente na Internet são riquíssimas e plurais. A proposta de se selecionar apenas um/a fotógrafo/a se baseia na visão de que variações estéticas muito grandes poderão, nesse primeiro momento, produzir um excesso de informações que, em lugar de promover olhares mais aguçados, possivelmente cansarão o grupo e atingirão sua capacidade de concentração.

Não será, ainda, momento para fixação de conceitos, mas apenas uma oportunidade de trocas de conhecimentos. No entanto, nesse momento,

\footnotetext{
5 Sebastião Ribeiro Salgado Júnior (Aimorés, MG, 1944) é um famoso fotógrafo brasileiro. Foi internacionalmente reconhecido e recebeu praticamente todos os principais prêmios de fotografia do mundo como reconhecimento por seu trabalho. Fundou em 1994 a sua própria agência de notícias, "As Imagens da Amazônia", que representa o fotógrafo e seu trabalho. Salgado e sua esposa Lélia Wanick Salgado, autora do projeto gráfico da maioria de seus livros, vivem atualmente em Paris. O casal tem dois filhos. Fonte: obvious: http://lounge.obviousmag.org/cafe_nao_te_deixa_mais_cult/2014/04/por-de-trasdas-fotografias-de-sebastiao-salgado.html\#ixzz60dFZak1q. Consulta realizada em 15 de agosto de 2019.
} 
será fundamental tocar na questão do sentido do "Belo" e discutir com o grupo o que, para seus/suas participantes, tornaria uma fotografia bonita. Um modo eficaz de desconstruir visões culturalmente construídas é trazer fotografias que permitam transformar essas visões. Como exemplo, cito esta fotografia de Sebastião Salgado:

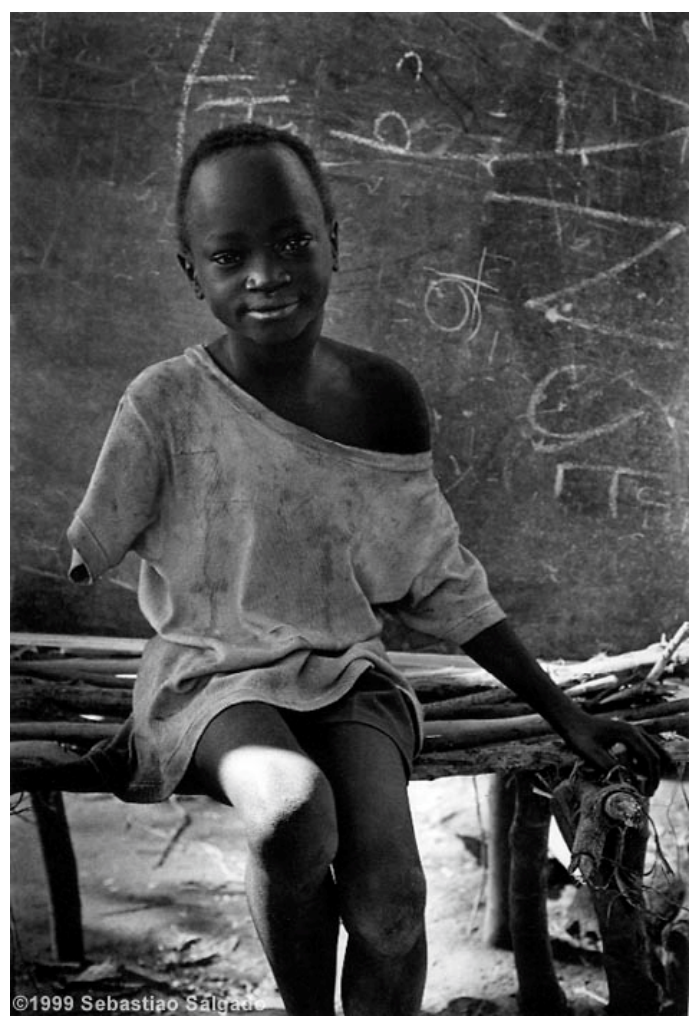

Imagem $1^{6}$

Depois de perguntar aos/às discentes se considerariam essa uma "bela" fotografia e de ouvir suas respostas e tecer comentários que possam explorar o que foi dito, o/a docente, como mediador/a da leitura, pode destacar - caso isso não tenha partido do próprio grupo - a beleza que reside no contraste entre a sugestão de sofrimento trazida tanto pelo fato de a criança não ter um braço como pelos elementos espaciais que caracterizam uma

${ }^{6}$ Disponível em http://historiadelartepublicdadb.blogspot.com/?q=Sebasti\%C3\%A3o+Salgado. Consulta realizada em 08/04/2020. 
realidade de muita pobreza e o semblante suave e terno dessa criança. Ao associar beleza a esse contraste, que provoca uma reflexão sobre a capacidade humana de superar as adversidades, o/a docente estará estimulando o grupo a abandonar possíveis conceitos prévios acerca do que seria uma imagem do "belo" e olhar para a fotografia buscando encontrar o modo que o/a fotógrafo/a encontrou para captar a beleza do mundo. Também é interessante explorar a sugestão de a criança estar em um ambiente escolar e debater os elementos que levam a essa visão.

Como tarefa complementar, pode-se propor pesquisas em grupo sobre fotógrafos/as renomados/as e seleção de algumas imagens para serem apresentadas à turma em encontro posterior. Caberá ao/à docente definir a carga horária a ser destinada a essa primeira etapa.

\section{Etapa 2: “Campo semântico": um lugar onde se semeiam sentidos}

Essa etapa se relaciona ao investimento na transformação do "ver" em "olhar". Dependendo do nível do grupo, o/a docente pode explicar, conceitualmente, o que quer dizer "campo semântico" - que poderia ser traduzido, de forma mais didática e simples, como uma "corrente de imagens ou palavras" por trás das quais há uma "corrente de ideias". Caso o/a docente opte por não fazer isso, basta propor ao grupo a "leitura" visual de algumas fotografias, seguindo o critério de pedir que os/as alunos/as observem, individualmente, cada foto (sugiro trabalhar, sequencialmente, com três fotografias diferentes ainda do/a mesmo/a fotógrafo/a e abrir espaço para algumas fotografias de outro/a fotógrafo/a que cada grupo tenha levado para a aula) e que, a partir dessa observação, registrem no papel palavras que lhes venham à cabeça. Assim que cada lista esteja pronta, o/a docente proporá a verificação das palavras coincidentes e diferentes, buscando que os/as discentes apresentem os porquês de terem pensado nas palavras que escreveram.

A experiência de observação desse repertório de palavras por eles/as registrado deve ser oral e paulatina, ou seja, sem pressa ou precipitação, o/a docente deve tentar chegar próximo do esgotamento de ideias. Para isso, pode contribuir sugerindo, para cada imagem, questões como: “E não poderíamos 
pensar na palavra X a partir dessa imagem? Sim? Não? Por quê?" A proposta é que as ideias associadas a cada imagem mostrem para os/as discentes que, quando aprendemos a olhar o mundo à nossa volta com mais sensibilidade e atenção, podemos ampliar nossa percepção sobre detalhes que, anteriormente, não havíamos percebido.

Como tarefa complementar, pode-se sugerir um exercício a ser feito em casa, no qual, a partir de uma imagem dada, cada aluno/a, além da série de palavras que venham à sua mente, componha pequenas frases com essas palavras, estabelecendo alguma relação com a própria fotografia.

\section{Etapa 3: "Fotopoesia": a arte de compor fotopoemas}

Essa etapa se prestará à apresentação do gênero "fotopoema". Sugiro que a etapa tenha início com a exibição de uma série de fotopoemas (cinco ou seis), sem antecipação de conceitos. Essa exibição poderá ser comparada com as anteriores exibições de fotografias, de modo que possa partir do próprio grupo a observação de que, na exibição dessa etapa, os textos que integram as imagens mantêm um diálogo com os elementos que fazem parte da fotografia.

Para a realização dessa mostra, disponibilizo, no site "miXturas", diversos fotopoemas de minha autoria. Mas é possível encontrar fotopoemas em pesquisas na Internet. Ao mesmo tempo, sugiro que o/a docente, caso se sinta seguro, surpreenda o grupo com um fotopoema de sua própria autoria.

Como exemplo, teço comentários sobre o fotopoema "Restou às ondas", reproduzido na sequência (disponível no site), imaginando um grupo de estudantes do segundo segmento do Ensino Fundamental ou de alunos/as do Ensino Médio: 


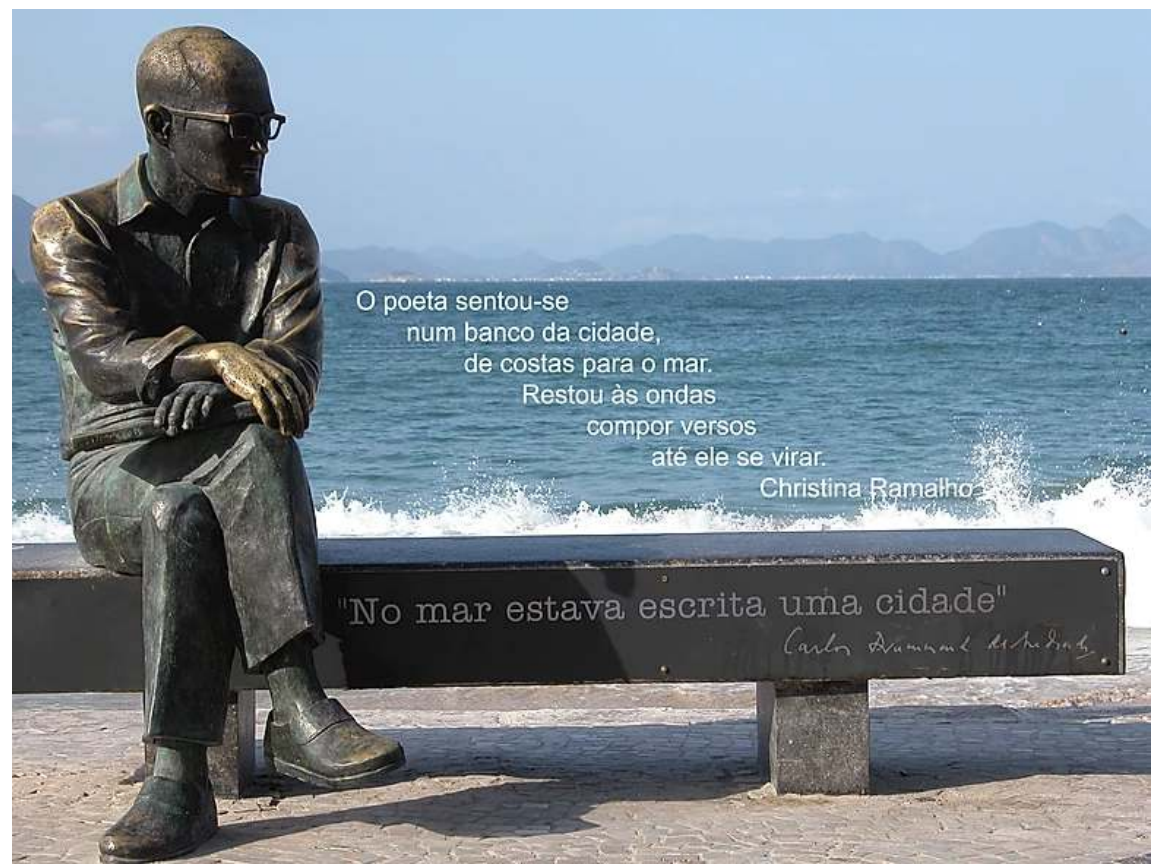

Imagem 2

Após ouvir os comentários do grupo, caberá ao/à docente não só explorar esses comentários, como trazer à tona alguns aspectos caso não venham a ser colocados pelo grupo, a saber: a foto foi tirada na cidade do Rio de Janeiro, no Posto 6, na praia de Copacabana; a fotografia apresenta uma famosa escultura do mineiro Leo Santana - inaugurada em 2002 - que nela retratou o poeta também mineiro Carlos Drummond de Andrade; o banco traz um verso de Drummond, extraído do poema "Mas viveremos" (A rosa do povo, 1945); os versos do poema de Christina Ramalho sugerem a forma de uma onda; há rimas no poema; o poema dialoga com a figura do poeta, entre outros.

Feito isso com alguns fotopoemas, o/a docente deve passar à conceituação do gênero. É importante que o/a docente faça referências especiais ao gênero lírico, recuperando ou inserindo, conforme o nível do grupo, o conceito de poema e de seus elementos estruturais. Ainda nesse momento, como já se afirmou nas seções anteriores deste artigo, é fundamental que o/a docente volte à questão do "belo", que, no caso da arte da Fotopoesia, resulta também da harmonia entre imagem e texto. 
Retomando o fotopoema "Restou às ondas" como exemplo, o/a docente poderia mostrar como as palavras do poema, feito para e a partir da fotografia, estão no campo semântico que a imagem traz: poeta, banco, cidade, costas, mar, ondas, versos. O poema, ao inserir a ideia de "até ele se virar", sugere o ponto de vista que o mar tem da própria escultura ou do próprio poeta.

Para encerrar essa etapa, o/a docente deve explorar o sentido amplo da palavra "poesia", conduzindo o grupo à percepção de que um fotopoema nasce quando um poeta percebe a "poesia" de uma imagem fotográfica e resolve interagir com ela. É interessante também que o/a docente aborde a questão dos direitos autorais, sublinhando que quando o/a fotógrafo/a é também o/a autor/a do poema, não há exigências de autorização para o uso da imagem.

\section{Etapa 4: Sobre técnicas da fotografia e da versificação}

Nessa etapa, o/a docente apresentará ao grupo algumas informações sobre técnicas da fotografia, sempre levando em consideração o nível do grupo com o qual estiver trabalhando. Sugiro, como fonte, livros como $O$ guia completo da fotografia digital(2006) ou sites disponíveis na Internet, dos quais o/a docente extrairá informações sobre luz, enquadramento, técnicas específicas para se fotografarem pessoas, paisagens, cenas urbanas, natureza, objetos, ações etc., qualidade da fotografia, efeitos alcançados em programas ou aplicativos para se trabalhar com imagens etc. Claro está que o conjunto de informações levado para a aula dependerá diretamente de uma série de características de grupo: faixa etária, nível escolar, acesso ao mundo digital, acesso ao uso de câmeras fotográficas ou do aparelho celular, além de curiosidades que o grupo manifeste espontaneamente.

A esse conjunto de informações se somará outro, referente à estrutura da versificação. Como poemas que compõem fotopoemas são, na grande maioria das vezes, curtos, porque precisam ser integrados à imagem de forma harmônica, sem contraste forte de cores ou sobreposição excessiva das palavras aos elementos que compõem a fotografia, sugiro que o/a docente leve poemas bem curtos para serem lidos e observados pelo grupo. Os haicais, por 
exemplo, são interessantes. A ideia de campo semântico pode ser retomada, agora a partir de poemas e não de imagens.

Essa abordagem não pode ser exaustiva, para não comprometer a qualidade da recepção, mas deve incluir algumas referências ao trabalho do gênero lírico com as figuras de linguagem. Dependendo do grupo, o/a docente pode eleger três ou quatro figuras de linguagem e mostrar como elas se fazem presentes nos poemas apresentados.

Como tarefa complementar, o/a docente pode solicitar que, no próximo encontro, cada estudante apresente uma fotografia de sua autoria, na qual ele/a reconheça haver tanto a qualidade "técnica" na forma final como alguma "poesia" no conteúdo. Para isso, deve motivar cada aluno/a a buscar a "poesia das coisas", salientando que pode estar num gesto das mãos de suas mães, no modo de dormir de seus animaizinhos de estimação, em uma flor que nasceu no jardim, em algum ângulo da própria rua onde moram etc.

Ainda como parte dessa etapa, as fotografias trazidas pelos membros do grupo devem ser exibidas individualmente. O/A docente deve mostrar ao grupo quais, entre as imagens exibidas, são mais adequadas, tecnicamente falando, para a inserção de textos. Para isso, devem ser observados os "espaços vazios" ou mais uniformes das imagens, onde se poderia inserir um texto. Além desses aspectos, o/a docente deve salientar o potencial poético de cada imagem, estimulando o grupo a entrar em contato, através do "olhar" com o campo semântico que cada fotografia apresenta. Dependendo do número de participantes, pode ser necessário ter mais de uma aula para essa experiência. Feito isso, o/a docente realizará um exercício de criação de fotopoemas, solicitando que cada aluno/a escreva um pequeno poema para a imagem preferida, dando liberdade para que os/as alunos/as interajam com fotografias de seus/suas colegas.

\section{Etapa 5: Um projeto temático de criação de fotopoemas}

Realizadas todas as etapas anteriores, é hora de propor à turma um projeto temático para a criação de fotopoemas, de modo que o grupo possa compor uma mostra a ser exibida, na forma de fotopoemas impressos, na própria sala, na escola ou em outro local, ou, virtualmente, em algum canal 
virtual disponível. O/A docente deve conduzir o debate para a definição do tema, observando que a proposta escolhida seja realmente viável, visto que pode haver casos em que alguns/mas alunos/as não tenham acesso ao tema proposto. Por exemplo, se a turma decidir fazer fotopoemas a partir de fotografias de seus animaizinhos de estimação e alguns membros do grupo não tiverem animais em casa, será complicado envolver todo o grupo na atividade. Caso não se chegue a essa definição espontaneamente ou o/a docente perceba que a escolha que está sendo encaminhada tem pouco potencial para explorar o sentido do poético, o/a docente pode propor temas, sempre considerando, cuidadosamente, o perfil do grupo.

O/a docente deve enumerar, com clareza, todos os cuidados necessários para a criação dos fotopoemas: a) seleção de fotografias nas quais se possa perceber a beleza ou o poético, que leva a pensarmos e sentirmos além da imagem; b) boa qualidade das fotografias, para que, em caso de impressão, possa se optar por tamanhos maiores de papel fotográfico, como o A3; c) trabalho com o texto lírico para se chegar ao efeito mais interessante, o que inclui o trabalho com figuras de linguagem, uso ou não de rimas, de divisão em estrofes, de efeitos como o deslocamento de palavras, o uso de letras maiúsculas etc.; d) perfeita harmonia entre o texto e a imagem, e, nesse sentido, cabe mostrar claramente que um fotopoema não é um texto em prosa colocado sobre uma imagem bonita apenas para passar uma mensagem - como acontece com muitas mensagens que circulam em locais como o Whatsapp, o Instagram ou o Facebook-, mas que é resultado de duas artes integradas em uma só, o que exige um trabalho cuidadoso e criativo; e) definição da autoria, com decisão sobre a possibilidade de criações em dupla (uma pessoa fotografa, a outra faz o poema), se for o caso; f) uso ou não de programas ou aplicativos que alterem ou deformem, intencionalmente a imagem, de modo a compor um conjunto harmônico de fotopoemas; g) definição o número de fotopoemas que comporá a mostra; h) revisão final de todos os fotopoemas produzidos; i) debate final do grupo, apreciando, individualmente, cada fotopoema que integrará a mostra. Este último momento poderá ser bastante revelador para o/a o docente, que poderá dimensionar os efeitos da oficina em termos de letramento lírico. A grande questão a ser respondida será: aas atividades aproximaram os/as alunos/as da poesia do mundo e do texto lírico em si? 


\section{Etapa 6: Organização, divulgação e realização da mostra}

Definidos todos os fotopoemas que integrarão a mostra, caberá ao grupo, sob a coordenação do/a docente, organizar o evento, considerando sua forma (fotopoemas impressos ou mostra virtual), título, data, local, divulgação, modo de identificar cada fotopoema etc.

Após a realização da mostra, o/a docente deve criar um momento para que todos/as explanem suas impressões sobre todo o trabalho realizado.

\section{Conclusão}

Este artigo, dedicado à Fotopoesia e à sua possível presença em salas de aula de diferentes níveis de ensino como recurso para o letramento lírico ou para o aprofundamento da relação de estudantes com a poesia, de forma geral, e com o poema, de modo específico, apresentou diversas considerações, a partir dos distintos aspectos envolvidos na proposta de uma Oficina de interpretação e criação de fotopoemas.

De reflexões sobre a presença do poema nas salas de aula a abordagens teóricas e críticas sobre a linguagem da fotografia, busquei compor um conjunto de fundamentações que possa orientar pessoas que se interessem pelo tema, levando-as não só a multiplicar sugestões aqui dadas como a elaborar caminhos próprios para o desenvolvimento de atividades com a Fotopoesia, cuja natureza híbrida, impactante e plural certamente permitirá diversas outras iniciativas.

\section{Referências}

BORGES, Marilia Dammski; ARANHA, José Marcelo Aranha; SABINO, José. Fotografia de natureza como instrumento para educação ambiental. In: Ciência \& Educação, v. 16, n. 1, p. 149-161, 2010.

CEREJA, William Roberto. Ensino de Literatura:uma proposta dialógica para o trabalho com literatura. São Paulo: Atual, 2005.

COSSON, Rildo. Letramento literário: teoria e prática. São Paulo: Contexto, 2006. 
DUTRA, Alessandra; SANTOS, Gilvan José Ferreira dos, SILVA; Luciana Idaldo da. Uso das novas tecnologias para a produção textual do gênero fotopoema em inglês. In: Revista Contemporânea de Educação, v. 14, n. 30, maio/ago. 2019, p. 279-297.

FELIZARDO, Adair; SAMAIN, Etienne. A fotografia como objeto e recurso de memória. In: Discursos fotográficos, Londrina, v.3, n.3, 2007, p. 205-220.

FREEMAN, Michael. O guia completo da fotografia digital. Edição revista e actualizada. Tradução Marta Jacinto e Sérgio Filipe. Lisboa: Livros e Livros, 2006.

GENS, Armando. Sobre o poema, o poeta, o livro. In: SANTOS, Leonor Werneck dos; MARTINS, Georgina; GENS, Rosa. Literatura infantil e juvenil na prática docente. Rio de Janeiro: Ao Livro Técnico, 2010, p. 4-21.

KOURY, Mauro Guilherme Pinheiro. Fotografia e interdito. In: RBCS. Vol. $19 \mathrm{n}$, 54 fevereiro/2004, p. 129-141.

LAJOLO, Marisa. Do mundo da leitura para a leitura do mundo. São Paulo: Ática, 2006.

MAUAD, Ana Maria. Através da imagem: fotografia e história interfaces. In: Tempo, Rio de Janeiro, vol. 1, n, 2, 1996, p. 73-98.

MAUAD, Ana Maria. O olhar engajado: fotografia contemporânea e as dimensões políticas da cultura visual. In: ArtCultura, Uberlândia, v. 10, n. 16, jan.-jun. 2008, p. 33-50.

PAULINO, Graça; COSSON, Rildo. Letramento literário: para viver a literatura dentro e

fora da escola. In: ZILBERMAN, Regina; RÖSING, Tania (Org). Escola e leitura: velha crise; novas alternativas. São Paulo: Global, 2009.

PAZ, Octávio. O arco e a lira. Trad. Olga Savary. Rio de Janeiro: Nova Fronteira, 1982.

PINHEIRO, Hélder. Poesia na sala de aula. Campina Grande: Bagagem, 2007.

RAMALHO, Christina. A poesia é o mundo sendo: o poema na sala de aula. In: Revista da Anpoll, no 36, Florianópolis, Jan./Jun. 2014, p. 330-370.

RODELLA, Cibele Abdo. A intencionalidade da imagem fotográfica poética e da imagem fotográfica no Jornalismo. In: Anais do Encontro Nacional dos Estudos da Imagem 2, 2009. Londrina: Universidade Estadual de Londrina, 2009, 10471055. 
http://www.uel.br/eventos/eneimagem/anais/trabalhos/pdf/Rodella_Cibele $\% 20$ Abdo.pdf. Consulta realizada em 12/04/220.

SAMAIN, Etienne. As peles da fotografia: fenômeno, memória/arquivo, desejo. In: Visualidades. Goiânia v.10 n.1, jan-jun 2012, p. 151-164.

Recebido em 29 de abril de 2020.

Aceito em 20 de junho de 2020. 